\title{
EDUKASI PENINGKATAN KESADARAN MASYARAKAT KOTA JAYAPURA DALAM MENJAGA DAN MELESTARIKAN LINGKUNGAN
}

\author{
Muhammad Sawir \\ Universitas Yapis Papua \\ Email: muhammadsawir76@yahoo.com
}

\begin{abstract}
ABSTRAK. Kegiatan ini merupakan implementasi dari pengabdian kepada masyarakat dalam bentuk penyuluhan terbatas. Adapun tujuan dari kegiatan yang telah diselenggarakan adalah memberikan edukasi, dan mengajak masyarakat Kota Jayapura agar menjaga serta melestarikan lingkugan sekitar. Kegiatan ini dilaksanakan pada tanggal 13 Februari 2020, menggunakan pendekatan bersifat persuasif edukatif dengan metode ceramah, diskusi, dan praktik/diskusi yang terbagi dalam empat tahapan: persiapan, pelaksanaan, serta akhir kegiatan. Hasil kagiatan menggambarkan bahwa masyarakat peserta kegiatan mengalami peningkatan wawasan, pengetahuan, dan mereka merasakan manfaat dari pelaksanaan kegiatan. Selanjutnya, kegiatan berikutnya dengan skala jumlah lebih luas dan kegiatan ini ditingkatkan menjadi beberapa pelatihan sangat dibutuhkan.
\end{abstract}

Kata kunci: Edukasi; masyarakat; lingkungan

ABSTRACT. This activity is an implementation of community service in the form of limited counseling. The purpose of the activities that have been carried out is to provide education, and invite the people of Jayapura City to maintain and preserve the surrounding environment. This activity was carried out on February 13, 2020, using an educative persuasive approach with lecture, discussion, and practice/discussion methods which were divided into four stages: preparation, implementation and end of the activity. The activity results illustrate that the community participating in the activity experienced an increase in insight, knowledge, and they felt the benefits of implementing the activity. Furthermore, subsequent activities on a broader scale and these activities will be increased to become more needed.

Key words: Education; community; environment

\section{PENDAHULUAN}

Lingkungan seperti diketahui merupakan tempat atau kawasan hidup manusia, hewan, dan tumbuhan (Karim, 2017). Lingkungan sebagaimana termaktub dalam Undang-undang (UU) Nomor 32 Tahun 2009 yakni digambarkan sebagai kesatuan ruang dengan semua benda, daya, keadaan, dan makhluk hidup, termasuk manusia dan perilakunya, yang mempengaruhi alam itu sendiri, kelangsungan perikehidupan, dan kesejahteraan manusia serta makhluk hidup lain. Salah satu tujuan perlindungan dan pengelolaan lingkungan hidup adalah melindungi wilayah Negara Kesatuan Republik Indonesia (NKRI) dari pencemaran dan/atau kerusakan lingkungan hidup (Kadiyono \& Harding, 2019). Kawasan inilah yang kemudian membentuk sebuah mata rantai ekosistem antar makhluk hidup (hayati) dan non-hayati (Hutapea \& Suwandono, 2014). Kemudian secara ekspilisit, keseimbangan ekosistem lingkungan manusia dipengaruhi oleh beberapa unsur antara lain: tatanan pola hidup, perubahan tata letak kawasan, dan pengaruh lainnya baik langsung maupun tidak langsung (Komariah, Yusup, Saepudin, \& Rodiah, 2017).

Indonesia adalah negara dalam belahan khatulistiwa dengan luas bentang alam yang terdiri atas pulau-pulau, lautan, hutan dan pegunungan. Setiap wilayah di Indonesia memiliki tekstur topografi yang bervariasi, hal tersebut menjadikan uniknya nusantara. Salah satu wilayah dengan tingkat keunikan tersendiri adalah Kota Jayapura Provinsi Papua. Berdasarkan data pendahuluan penulis tahun 2020: (1) Luas Kota Jayapura adalah $940 \mathrm{Km}^{2}$ atau 940.000 Ha dengan total jumlah penduduk 297.775 jiwa, dengan kepadatan penduduk 283 jiwa/Km. Secara astronomis Kota Jayapura terletak pada 1²8'17,26'LS - 358'082'"LS dan 137³4'10,6'BT - 14100'8'22”BT; (2) Secara administratif, Kota Jayapura terdiri dari 5 (lima) distrik yaitu Distrik Jayapura Utara, Distrik Jayapura Selatan, Distrik Abepura dengan, Distrik Heram dan Distrik Muara Tami, terbagi menjadi 25 kelurahan dan 14 kampung berbatasan dengan Samudera Pasifik disebelah utara, Papua Nugini (PNG) disebelah timur, Kabupaten Keerom disebelah selatan, dan Kabupaten Jayapura disebelah barat; dan (3) Secara topografi daerah Kota Jayapura cukup bervariasi, mulai dari daratan, yang landai sampai berbukit-bukit/gunung, dimana terdapat $\pm 60 \%$ daerah tidak layak huni (nonbudidaya) karena terdiri dari daerah perbukitan yang terjal dengan kemiringan diatas $40 \%$, rawarawa berstatus konservasi atau hutan lindung. Kota Jayapura berada pada ketinggian $1-700 \mathrm{~m}$ di atas permukaan laut (dpl) dan hanya $\pm 40 \%$ lahan yang layak huni (budidaya) dan hamparan itu sebagian besar di Distrik Muara Tami yang merupakan wilayah perbatasan dengan (PNG). 
Kota Jayapura dengan perkembangan dan kemjuan kemudian tidak lepas dari permasalahan lingkungan. Seperti tercermin dari data penulis bulan Januari 2020 bahwa potensi kerusakan lingkungan pada wilayah kelurahan Ardipura Distrik Jayapura Selatan, hal ini diakibatkan oleh: (1) Aktivitas usaha penggalian batu karang untuk usaha batu tela; (2) Penggalian tanah kawasan perbukitan; (3) Penebangan pohon dan berkurangnya debit sumber mata air bersih; (4) Sampah rumah tangga; dan (4) Usaha peternakan yang belum termanajemen dengan baik. Selanjutnya, kendala yang masih dihadapi yaitu belum adanya partisipasi masyarakat sekitar untuk memiliki kepedulian dalam mencegah potensi-potensi kerusakan lingkungan yang timbul. Pekerjaan berat menanti sebab sumber daya alam (SDA) tersebut tentu ada yang dan tidak dapat diperbaharui dalam waktu yang singkat.

Oleh karenanya, permasalahan lingkungan merupakan suatu fenomena yang memerlukan perhatian khusus bagi semua masyarakat (Komariah, Yusup, Saepudin, \& Rodiah, 2020). Maka setiap orang diharapkan ikut berpartisipasi dan bertanggung jawab untuk mengatasi potensi kerusakan lingkungan, baik yang diakibatkan oleh aktivitas manusia ataupun siklus alam (Lambrakis, Stournaras, \& Katsanou, 2011). Apabila kawasan-kawasan yang ada mampu dikelola dengan baik tentu akan memberikan sumbangan dan manfaat bagi masyarakat sekitar itu sendiri (Baihaki, 2018). Beragam carapun dapat dilakukan, antara lain: tidak menebang pohon sembarangan, tidak membuang sampah sembarangan dan mencemari lingkungan laut (Nisa, 2014). Adapun upaya lain yang juga dapat dilakukan yakni dengan menanam pohon (Choiriyah, 2015), mencari sumber mata air baru dan membuat penampungan di daerah perbukitan tinggi serta tempat-tempat resapan air (Azhar, 2018), serta menghentikan aktivitas perusakan kawasan biota laut (Sinulingga, Baiquni, \& Purnama, 2015). Kurangnya kesadaran masyarakat terhadap bahaya kerusakan lingkungan dan rendahnya pengetahuan menyebabkan dampak serius dikemudian hari (Istiawan \& Kastono, 2019).

Berdasarkan beberapa permasalahan dan uraian yang telah dijelaskan di atas, sebagai seorang akademisi penulis memiliki kepedulian untuk melaksanakan Tri Dharma Peguruan tinggi yakni dengan mengadakan edukasi peningkatan kesadaran masyarakat Kota Jayapura dalam menjaga dan melestarikan lingkungan. Tulisan ini menjadikan gambaran pelaksanaan kegiatan PKM (pengabdian kepada masyarakat) yang berlangsung selama satu hari dan terbagi menjadi dua sesi. Tujuan dari PKM ini adalah untuk memberikan edukasi, dan mengajak masyarakat Kota Jayapura agar menjaga serta melestarikan lingkugan sekitar, sehingga ekosistem antar makhluk hidup (hayati) dan non-hayati dapat terpelihara dengan baik serta mencegah potensipotensi kerusakan lingkungan.

\section{METODE}

Kegiatan PKM ini memberikan edukasi tentang peningkatan kesadaran masyarakat Kota Jayapura dalam menjaga dan melestarikan lingkungan. Keseluruhan kegiatan berdurasi selama 1 (satu) hari, terbagi dalam dua sesi diawali oleh survei awal untuk masukan data rancangan detail kegiatan, dengan sasaran kegiatan adalah warga masyarakat kelurahan Ardipura Distrik Jayapura Selatan Kota Jayapura Provinsi Papua yang berjumlah 25 orang. Kegiatan PKM ini menggunakan pendekatan bersifat persuasif edukatif dengan metode ceramah, diskusi, dan praktik/diskusi. Alur implementasi PKM ini meliputi tahapan sebagai berikut:

1. Tahapan persiapan PKM yaitu: a. Menyusun dan menyiapakan materi kegiatan sertaproses perijinan PKM; b. Koordinasi dengan Lurah Ardipura; c. Koordinasi dengan Badan Lingkungan Hidup (BLH) Kota Jayapura ke lokasi PKM; dan d. Koordinasi dengan LP2M (Lembaga Penelitian dan Pengabdian Masyarakat) Universitas Yapis Papua.

2. Tahapan pelaksanaan/sosialisasi, meliputi: a. Menyiapkan sertifikat, berita acara dan berkas PKM yang dibantu tim LP2M; b. Peserta mengisi daftar hadir, dan pembagian leflaet materi penyuluhan; c. Sambutan Lurah Ardipura, dilanjutkan pemaparan materi pengabdi dan diskusi aktif bersama audiens; dan d. Melakukan evaluasi kegiatan, dimana pelaksana memberikan kesempatan bagi peserta mengisi lembar evaluasi yang bertujuan untuk mengetahui feedback dari peseta.

3. Tahapan akhir kegiatan meliputi: a. Focus group discussion (FGD) dan forum Musrengbang (musyawarah rencana pembangunan) Kota Japura yakni BLH Kota Jayapura, Kepala Distrik Kota Jayapura Selatan, perwakilan pejabat kelurahan Ardipura, pengabdi dan tim LP2M Universitas Yapis Papua; dan b. Pembuatan dan penysusunan laporan akhir PKM.

\section{HASIL DAN PEMBAHASAN}

Pengabdian pada masyarakat ini diberikan dalam bentuk penyuluhan yang bertempat di Balai Kelurahan Ardipura. Penyuluhan diikuti oleh 25 perserta yang terdiri dari perwakilan warga masyarakat dan pejabat kelurahan. Lokasi ini dipilih mengingat sangat strategis dan dapat dijangkau oleh pesertakegiatan. Berikutmerupakanuraian mengenai tahapan yang dilakukan tim PKM mulai dari sebelum pelaksanaan hingga setelah pelaksanaan: 
1. Tahap awal kegiatan PKM ini, pengabdi melakukan survey kunjungan ke kawasan industri batu tela, tempat penggalian tanah timbunan, tempat peternakan babi. Kemudian pengabdi juga melanjutkan kunjungan ke beberapa rumah warga untuk mensosialisasikan rencana kegiatan, selanjutnya pengabdi mengurus perizinan kegiatan ke kantor kelurahan dan berdiskusi dengan lurah Ardipura.

2. Pelaksanaan kegiatan penyuluhan diberikan dalam bentuk metode ceramah, diskusi, dan praktik/ diskusi. Materi disampaikan dalam bentuk ceramah dengan alat bantu LCD (liquid crystal display) projector, dan disajikan dalam bentuk paparan ppt (powerpoint). Melalui pemaparan ini, peserta diarahkan untuk mengerti dan memahami pemanfaatan SDA dan manajemen lingkungan. Uraian lengkap dari pelaksanaan kegiatan PKM seperti di bawah ini:

a. Penjelasan singkat SDA (hayati dan nonhayati).

b. Penjelasan lingkugan sehat, bersih, sehat, dan potensi ekonomi.

c. Penjelasan konsep manajemen pemanfaatan lingkungan berbasis manajemen kearifan lokal.

d. Penjelasan dampak dan potensi kerusakan lingkungan secara berkelanjutan.

e. Penjelasan teknologi dan promosi berbasis media sosial digital.

Peserta yang mengikuti kegiatan sangat antusias, hal ini ditunjukkan dengan respon yang diberikan melalui beragam pertanyaan disela pamaparan materi. Kegiatan PKM ini menjadi forum silaturahmi sekaligus menambah pengetahuan baru berkaitan pengelolaan lingkungan dan bagaimana memberikan kesadaran kepada masyarakat untuk memiliki kepedulian dalam menjaga serta melestarikan lingkungan tersebut. Penyuluhan ini telah dilaksanakan secara baik dengan menghadirkan warga masyarakat dari beberapa ragam budaya, etnis, agama, pekerjaan, dan gender.

Selain materi paparan dari pengabdi, kegiatan ini dilanjutkan dengan membagi warga dalam beberapa kelompok dan memberikan waktu bagi mereka untuk memunculkan ide. Teknik ini diambil untuk mengetahui ide-ide segar dari peserta, hal tersebut menjadi penting untuk menggali potensi kearifan lokal dan pentingnya mengenal adat istiadat masyarakat. Berikutnya perwakilan masing-masing kelompok memberikan pandangan serta pendapat tentang bagaimana sebenarnya upaya menjaga dan melestarikan lingkungan. Pemahaman tersebut sangatlah penting sebagai modal untuk promosi sekaligus potensi nilai ekonomis salah satunya melalui media sosial.
Sesi lanjutan dari kegiatan ini kemudian dimanfaatkan untuk memantikide kreativitas peserta. Diskusi dilakukan lebih intensif untuk menggali potensi SDA, budaya dan peluang wirausaha. Oleh karenanya, dalam tahapan ini peserta saling tukar pikiran dan ide. Kemudian, terlihat dari pelaksanaan diskusi tersebut, peserta antusias bertanya dan menuangkan gagasannya dalam bentuk tertulis. Peserta kegiatan kemudian menyadari bahwa kegiatan inilah yang dirasa perlu untuk dilakukan kembali. Peserta juga belum menunjukan berbagai permasalahan yang ada di lingkungannya, seperti manajemen peternakan, saluran limbah, dan izin usaha pertambangan.

Kemudian dilanjutkn materi berikutnya yang dilanjutkan dengan pemaparan kembali tentang kearifan lokal, dampak dan potensi kerusakan lingkungan, serta pemanfaatan teknologi dalam promosi keunggulan wilayah. Sesi ini berlangsung sangat menarik karena banyak lahir pemikiran atau gagasan tentang bentang alam/kearifan lokal yang mereka tuangkan dalam bentuk tulisan, foto dan video. Secara umum peserta pelatihan yang sangat antusias mengikuti kegiatan pelatihan ini, hal ini tidak terlepas dari ketertarikan peserta setelah diberi pengetahuan dan pemahaman akan pentingnya memanfaatkan dan melestarikan lingkungan, serta peran sosial media digital untuk promosi. Bahkan di akhir kegiatan peserta masih terus bertanya dan melontarkan ide-ide secara personal kepada narasumber.

3. Setelah semua kegiatan telah dilaksanakan, tim PKM mulai menyusun pembagian tugas laporan akhir. Selain itu dilakukan penentuan tanggal batas pengumpulan penyusunan laporan. Kemudian dilanjutkan dengan implementasi dari proses kegiatan PKM ini berupa FGD bersama Musrengbang Kota Jayapura. Hal ini menjadi sesuatu yang sangat penting karena tujuan dan sararan kegiatan selain disampaikan kepada peserta kegiatan juga dapat menjadi bahan masukan serta rujukan kepada stakeholder terkait dalam bidang lingkungan hidup maupun pemberdayaan ekonomi mikro.

Berdasarkan aspek yuridis formal, dasar hukum pemerintah Kota Jayapura dalam upaya menjaga dan melestarikan lingkungan sebagaimana termaktub dari sumber utama yakni Undang-undang Pertambangan (UU Minerba) No. 4 Tahun 2009 tentang Pertambangan Mineral dan Batubara, serta Peraturan Walikota Jayapura No. 14 Tahun 2011 tentang Pengelolaan Usaha Pertambangan Mineral Bukan Logam dan Batuan, dalam peraturan tersebut dinyatakan bahwa setiap usaha penambangan 
harus memiliki ijin Usaha Pertambangan (IUP) sesuai UU Minerba pasal 1 butir 7, namun yang terjadi adalah masih banyaknya kegiatan potensi perusakan lingkungan, salah satunya yaitu dengan penggalian tanah timbunan dan penebangan pohon, serta pembuangan limbah dan sampah yang belum termanajemen dengan baik. Adapun, belum terlibatnya masyarakat secara aktif dalam setiap program pelestarian lingkungan merupakan pekerjaan rumah bagi pemerintah Kota dimanapun berada (Prastyowati, 2015), selain itu terobosan dan peran serta masyarakat terdidik dalam memberikan wawasan pengetahuan akan pentingnya pemanfaatan dan pelestarian lingkungan sangat diperlukan dalam upaya menjaga keseimbangan ekosistem alam (Antara, 2015). Kegiatan PKM yang telah dilaksanakan menjadi titik balik dimana masyarakat dan akademisi bersinergi salam menjaga dan melestarikan lingkungan sekitar.

Keberhasilan kegiatan PKM ini merupakan contoh nyata bagaimana antusiasme masyarakat Kota Jayapura dalam rangka kepedulian akan pentingnya menjaga dan merawat lingkungan sebagai kawasan hunian dan pengenalan maupun pemanfaatan teknologi digital. Era disrupsi saat ini memberi ruang dimana manusia, alam sekitar, dan teknologi menjadi satu kesatuan. Pemanfaatan dan pelestarian lingkugan juga perlu ditunjang dengan sarana teknologi yang memadai, kemudian dengan itu akhirnya juga perlu untuk dikembangkan menjadi promosi berbasis kearifan lokal yang memberikan manfaat. Arti penting dari kegiatan PKM ini adalah bahwa dengan adanya program-program penyluhan lingkungan kemudian masyarakat semakin termotivasi, memiliki wawasan, dan pengetahuan tentang pengelolaan dan pemanfaatan yang baik. Oleh sebab itu, kemudian menjadi penting untuk dilanjutkan dengan cakupan skala kegiatan yang lebih luas dan ditingkatkan menjadi pelatihan yang memiliki muatan kurikulum bersifat simultan berkelanjutan.

\section{SIMPULAN}

Berdasarkan hasil data dan pembahasan di atas, selanjutnya dapat ditarik simpulan seperti di bawah ini: Secara umum peserta penyuluhan, yakni warga masyarakat Kelurahan Ardipura Distrik Jayapura Selatan Kota Jayapura mengalami peningkatan wawasan dan pengetahuan mengenai pemanfaatan dan pelestarian lingkungan sekitar dengan benar; Meningkatnya pemahaman peserta, baik berupa sikap peserta tentang kearifan lokal dan potensi SDA, maupun kesadaran akan pemanfaatan media sosial untuk promosi produk sekitar kawasan.

\section{DAFTAR PUSTAKA}

Antara, G.E. (2015). Peningkatan Inovasi Teknologi Tepat Guna dan Program Berbasis Pemberdayaan Masyarakat Untuk Memajukan Industri Kreativ di Bali. Jurnal PASTI, IX (3) 257-268.

Azhar, M. (2018). Implementasi Kebijakan Energi Baru dan Energi Terbarukan dalam Rangka Ketahanan Energi Nasional. Adminitrative Law \& Governance Journal, 1 (4) 398-312.

Baihaki, M.A. (2018). Peran Dinas Lingkungan Hidup Terhadap Pengelolaan Kualitas Air dan Pengendalian Pencemaran Air di Kota Metro. Skripsi. Lampung: Fakultas Hukum Universitas Lampung.

Choiriyah, S. (2015). Analisis Pekerjaan Basement (Pekerjaan Galian dan Diaphragm Wall) pada Metode Top-Down dengan Alat Berat Ditinjau dari Aspek Teknik, Waktu, dan Biaya. EXTRAPOLASI Jurnal Teknik Sipil, 8 (2) $163-168$.

Hutapea, H. \& Suwandono, D. (2014). Perencanaan Pembangunan Perumahan Baru dan Strategi Pengadaan Tanah Bagi Masyarakat Berpenghasilan Rendah di Kecamatan Banyumanik. Jurnal Ruang, 2 (4) 371-380.

Istiawan, N. \& Kastono, D. (2019). Pengaruh Ketinggian Tempat Tumbuh terhadap Hasil dan Kualitas Minyak Cengkih (Syzygium aromaticum(L.) Merr. \& Perry.) di Kecamatan Samigaluh, Kulon Progo. Vegetalika, 8 (1) 2741.

Kadiyono, A. \& Harding, D. (2019). Peningkatan Perilaku Hidup Bersih dan Sehat (PHBS) Berwawasan Lingkungan Pada Siswa SD Desa Cipacing Dan Cilayung-Jatinangor. Jurnal Pengabdian Kepada Masyarakat "Dharmakarya, 8 (4) 244-248.

Karim, A. (2017). Mengembangkan Kesadaran Melestarikan Lingkungan Hidup Berbasis Humanisme Pendidikan Agama. Edukasia: Jurnal Penelitian Pendidikan Islam, 12 (2) 309-330.

Komariah, N., Yusup, P. M., Saepudin, E. \& Rodiah, S. (2020). Diseminasi Informasi Peduli Lingkungan pada Masyarakat Desa Paledah Kabupaten Pangandaran. Jurnal Pengabdian Kepada Masyarakat "Dharmakarya, 9 (1) 34-37. 
Komariah, N., Yusup, P., Saepudin, E. \& Rodiah, S. (2017). Pendidikan Literasi Lingkungan Sebagai Penunjang Desa Wisata Agro Kecamatan Padaherang Kabupaten Pangandaran. Jurnal Pengabdian Kepada Masyarakat "Dharmakarya, 6 (2) 111-115.

Lambrakis, N., Stournaras, G. \& Katsanou, K. (2011). Advances in the Research of Aquatic Environment. Berlin: Springer. Berlin: Springer.

Nisa, H.(2014). Analisis Potensi Dan Pengembangan Wilayah Kabupaten Lebak Provinsi Banten.
Skripsi. Semarang: Fakultas Ekonomika dan Bisnis Universitas Diponegoro.

Prastyowati, S. (2015). Penanggulangan Kemiskinan dengan Pemanfaatan Teknologi Tepat Guna Poverty Prevention Through Right-using Technology Application. Jurnal PKS, 4 (3) 317-328.

Sinulingga, R., Baiquni, M. \& Purnama, S. (2015). Pengelolaan Sumberdaya Air untuk Pengembangan Pariwisata di Pulau Pari, Kepulauan Seribu, DKI Jakarta. Majalah Geografi Indonesia, 29 (2) 177-186. 